\title{
TRADISI LISAN HAHIWANG PADA PEREMPUAN DI PESISIR BARAT LAMPUNG
}

\author{
ORAL TRADITION OF HAHIWANG OF WOMEN \\ IN WEST COAST OF LAMPUNG
}

\author{
Ali Gufron \\ Balai Pelestarian Nilai Budaya Bandung \\ Jalan Cinambo No. 136 Ujungberung - Bandung \\ e-mail: uunhalimah76@gmail.com
}

\begin{abstract}
Abstrak
Artikel ini bertujuan menguraikan bagaimana tradisi hahiwang berkembang pada masyarakat 16 marga di Kabupaten Pesisir Barat, Lampung, yang dibagi menjadi empat bagian. Bagian pertama membahas hahiwang sebagai salah satu bentuk tradisi lisan. Bagian kedua membahas sistem kekerabatan yang bersifat patrilineal dan konsep patriarki pada masyarakat Pesisir Barat. Bagian ketiga membahas tentang bentuk dan struktur hahiwang. Dan, bagian terakhir membahas hahiwang dan dominasi laki-laki. Metode penelitian yang digunakan adalah deskriptif kualitatif. Adapun teknik untuk menjaring data dan informasi adalah wawancara dan observasi. Hasilnya, menunjukkan bahwa hahiwang lahir akibat dominasi patriarki yang mensubordinasikan perempuan Lampung Saibatin dalam bentuk aturan adat. Hahiwang merupakan ungkapan pengalaman dan perasaan jiwa perempuan Lampung Saibatin atas ketidakberdayaannya dalam menghadapi dominasi laki-laki. Hahiwang tidak bertujuan untuk menggulingkan kekuasaan patriarki, melainkan hanya sebagai ungkapan atas ketertindasan perempuan dalam bentuk ratapan yang dilantunkan. Namun dalam perkembangan selanjutnya, hahiwang dieksploitasi kaum patriaki menjadi sarana siar agama, pelengkap begawi adat, dan bahkan penarik simpatisan dalam Pemilihan Umum Kepala Daerah.
\end{abstract}

Kata kunci: hahiwang, perempuan, tradisi lisan, sistem kekerabatan, patriarki.

\section{Abstract}

This article aims to describe how the hahiwang tradition which develops in a community of 16 clan in West Coast District, Lampung, which is divided into four parts. The first part discusses hahiwang as one form of oral tradition. The second section discusses the patrilineal kinship system and the patriarchal concept of the West Coast community. The third section deals with the shape and structure of hahiwang. And, last part discusses hahiwang and male domination. The research method used is descriptive qualitative. The techniques getting the data and information are used interviews and observation. The result shows that hahiwang were born due to patriarchal dominance that subordinating Lampung Saibatin women in the form of custom rules. Hahiwang is an expression of experience and feelings of the female soul of Lampung Saibatin for his powerlessness in the face of male domination. Hahiwang does not aim to overthrow patriarchal rule, but only as an expression of women's oppression in the form of laments sung. However, in later developments, hahiwang exploited the patriarchs to be a means of religious broadcasting, supplements of traditional begawi, and even the pullers of sympathizers in the General Election of Regional Head.

Keywords: Hahiwang, Womens, oral tradition, kinship system, patriarchy. 


\section{A. PENDAhuluan}

Jauh sebelum manusia mengenal tulisan, proses pewarisan kebudayaan dilakukan dengan cara dituturkan dari satu generasi kepada generasi berikutnya. Cara penyampaiannya menurut Irwanto (2012:126), dapat melalui cerita rakyat (dongeng, legenda, mitologi), nyanyiannyanyian, sistem kognitif, adat istiadat, sarana ekspresi, sistem religi dan kepercayaan, kearifan lokal atau bentuk lainnya. Proses penyampaian secara lisan inilah yang kemudian disebut sebagai tradisi lisan.

Tradisi lisan dapat diartikan sebagai segala wacana yang diucapkan meliputi yang lisan dan yang beraksara atau sistem wacana yang bukan beraksara (Pudentia, 1998:vii). Kandungan wacana tersebut menurut Sedyawati (1996:5-6), sangat bervariasi serta mempunyai cakupan luas mulai dari uraian genealogis, sistem pengetahuan, ungkapan seremonial ritual, hingga seni tutur atau sastra lisan. Oleh Danandjaja (1998:54), sastra lisan atau sastra rakyat (folk literature) dianggap sinonim dengan folklor lisan karena merupakan bagian kebudayaan yang tersebar dan diwariskan turun-temurun baik yang disertai dengan gerak isyarat atau alat pembantu pengingat. Sebagai bagian dari kebudayaan, sastra lisan tidak lepas dari pengaruh nilai-nilai yang hidup dan berkembang di masyarakat. Ia memberikan ciri khas daerahnya sendiri yang menganut nilai-nilai tertentu yang mengikat masyarakat agar tetap utuh mempertahankan tradisinya.

Di daerah Lampung, tempatnya di Kabupaten Pesisir Barat terdapat sejenis seni tutur yang disebut sebagai hahiwang. Hahiwang merupakan satu dari beberapa ragam karya sastra orang Lampung. Sanusi (2001:7) membagi karya sastra lisan etnis Lampung menjadi 5 (lima) macam, yaitu: Peribahasa (sesikun/sekiman); (2) teka-teki (seganing/teteduhan); (3) mantera (memmang, asihan, pebukkem/pebukkom, pengheppek/pengheppok, balung, jappeil jappi); (4) cerita rakyat (warahan); dan (5) puisi (paradinei/paghadini, papaccurl papaccogh/wawancan, pattun/adi-adi, bebandung, ringget/pisaan/highinghighing/wayak/ngehahaddo, hahiwang).

Sebagai bagian dari sastra lisan Lampung, hahiwang berupa ungkapan pengalaman dan perasaan jiwa atau tanggapan perempuan Lampung atas lingkungannya (dalam arti luas) yang diwujudkan dalam dunia fiksi melalui media bahasanya (bahasa Lampung) dalam bentuk tuturan. Hahiwang sendiri berasal dari kata dasar hiwang yang berarti menangis, mengisak, meratap atau penyesalan. Awalan /ha/ di depan kata /hiwang/ menunjukkan arti sangat yang memiliki makna "hiperbolisme"; yakni sedih yang amat sangat, kesedihan mendalam. Arti tersebut tergambarkan pada seni tutur hahiwang yang menyuarakan isi hati dengan lantunan suara yang menyayat.

Hahiwang berkembang pada masyarakat adat Saibatin/Peminggir, khususnya 16 Marga Pesisir Krui, Kabupaten Pesisir Barat. Bahasa yang digunakan dalam ber-hahiwang adalah bahasa Lampung subdialek Belalau atau lebih dikenal dengan dialek Api/"A" (Hadikusuma, 1996). Subdialek ini juga dipertuturkan oleh ulun Lampung Saibatin/Peminggir yang berdomisili di Melinting-Meranggai, Pesisir Rajabasa, Pesisir Teluk, Pesisir Semaka, Kedondong, Belalau, Way Tenong, Sumber Jaya, Ranau, Komering, Kayu Agung serta ulun Lampung Pepadun yang berdomisili di Way Kanan, Sungkay Utara, Natar dan Pubian (khufronimi9.wordpress.com).

Sejak kapan hahiwang muncul sudah tidak diketahui lagi. Sebab, apabila mengacu pada definisi folklor lisan seperti yang dikemukakan Danandjaja di atas, maka seni tutur diwariskan secara oral untuk dijadikan sebagai milik komunal. Jadi, sudah tidak mungkin lagi untuk menelusuri kapan serta siapa yang pertama kali menciptakannya. Satu hal yang menarik, tradisi ini masih tetap dilantunkan oleh sebagian orang, khususnya kaum 
perempuan Pesisir Krui. Oleh karena itu, penelitian tentang hahiwang perlu dilakukan dengan masalah: Bagaimana bentuk dan struktur hahiwang serta apa fungsi bagi masyarakat pendukungnya. Adapun tujuannya adalah untuk menggambarkan bentuk atau strukur hahiwang serta mengetahui fungsi bagi masyarakat khususnya kaum perempuan di 16 marga Pesisir Krui. Materi yang akan dibahas meliputi: struktur sosial masyarakat Pesisir Krui, bentuk dan struktur hahiwang, sistem kekerabatan masyarakat Pesisir Krui, dan aturan-aturan dalam sistem kekerabatan yang mengikat kaum perempuan berdasarkan prinsip patriarki.

Penelitian tentang hahiwang yang ada di Kebupaten Pesisir Barat masih belum banyak dilakukan orang. Dari penelusuran literatur hanya ada beberapa tulisan yang relatif lengkap membahas tentang hahiwang. Salah satunya adalah tulisan Fauzi Fattah pada harian Lampung Post terbitan 20 Juli 2013 dengan judul "Menyingkap Makna Filosofis Hahiwang". Dalam tulisannya Fattah membahas tentang makna filosofis hahiwang berjudul Janji Sebudi yang berkisah tentang kekecewaan seorang bujang karena sang kekasih menikah dengan orang lain. Menurut Fattah, walau berisi penderitaan seseorang "Janji Sebudi" juga mengandung makna filosofis yang dapat menggambarkan kehidupan orang Lampung, yaitu: agamis, patuh pada pimpinan adat, rendah hati, sabar, saling menghormati, dan kesederhanaan.

Selain Fattah, ada pula penelitian dari Kurnia (2010) yang berjudul "Fungsi Hahiwang pada Ulun Saibatin Krui Kecamatan Pesisir Tengah Lampung Barat". Dalam penelitiannya Kurnia mendefinisikan hahiwang yang diperoleh dari sastrawan Mamak Lawok sebagai puisi berbentuk cerita yang dibagi menjadi dua bagian, yaitu hahiwang agama dan adat. Hahiwang agama berisi syariat dan ajaran-ajaran Islam yang umumnya disenandungkan saat memperingati hari- hari besar agama Islam, sedangkan hahiwang adat berisi ketentuan adat tentang silsilah, perkawinan, dan lain sebagainya yang disenandungkan pada acara begawi adat. Berdasarkan kedua bentuk tersebut Kurnia menyimpulkan bahwa fungsi hahiwang adalah sebagai saran dakwah keagamaan serta pengingat orang Lampung akan adat istiadatnya. Seiring perkembangan zaman, fungsi ini telah bergeser menjadi alat bagi sebagian orang untuk mendapatkan perhatian publik.

Penelitian-penelitian tersebut menunjukkan bahwa aspek sistem kekerabatan yang bersifat patrilineal tidak menjadi sesuatu yang ditekankan oleh para peneliti. Fauziah Fattah lebih menekankan pada makna filosofis hahiwang yang bersumber dari jati diri orang Lampung. Penekanan Kurnia lebih pada fungsi hahiwang sebagai sarana berdakwah dan pengingat orang Lampung akan adat istiadatnya. Sedangkan penelitian ini lebih menekankan pada hubungan hahiwang dengan dominasi laki-laki yang mensubrodinasikan perempuan Lampung Saibatin.

\section{B. METODE PENELITIAN}

Metode yang digunakan dalam penelitian ini adalah deskriptif kualitatif. Teknik pengumpulan data dan informasi menggunakan wawancara dan observasi. Wawancara ditujukan kepada para pelantun hahiwang dan tokoh informal yang menguasai adat istiadat Lampung Saibatin di Pesisir Krui. Melalui wawancara dengan para informan yang dilakukan pada pertengahan bulan Juni 2016 dan awal bulan April 2017, diperoleh data dan informasi berupa: (1) definisi hahiwang; (2) struktur hahiwang; (3) pelantunan hahiwang, dan (4) struktur serta sistem kekerabatan masyarakat Pesisir Krui. Sementara, melalui observasi diperoleh data tentang lingkungan alam, pola pemukiman, dan perilaku masyarakat Pesisir Barat dalam kehidupan sehari-hari. 
Selain metode beserta teknik di atas, studi literatur (kepustakaan dan atau dokumentasi) juga dilakukan dalam kegiatan ini. Studi literatur dilakukan dalam rangka memeroleh pengertian atau konsep-konsep yang berkenaan dengan hahiwang, sistem kekerabatan, patriarki, dan gender. Adapun data-data yang berkenaan dengan Kabupaten Pesisir Barat, seperti posisi geografis, kependudukan, pola pemukiman, dan mata pencaharian diperoleh dari Badan Pusat Statistik Kabupaten Pesisir Barat.

\section{HASIL DAN BAHASAN}

\section{Sekilas tentang Kabupaten Pesisir Barat}

Kabupaten Pesisir Barat secara administratif termasuk dalam wilayah Provinsi Lampung dengan batas geografis sebelah utara dengan Kabupaten Lampung Barat dan Kabupaten Ogan Komering Ulu (Provinsi Sumatera Selatan); sebelah timur dengan Kecamatan Pematang Sawah dan Kecamatan Semaka; sebelah selatan dengan Samudera Hindia; dan sebelah barat berbatasan dengan Kabupaten Kaur (Provinsi Bengkulu). Kabupaten yang dibentuk berdasarkan Undang-undang Nomor 22 Tahun 2012 (Lembaran Negara Nomor 231, Tambahan Lembaran Negara Nomor 5364) yang diundangkan tanggal 17 November 2012 ini memiliki luas wilayah sekitar $2.907,23 \mathrm{~km}^{2}$ atau 495.04 ha dengan titik koordinat $4^{\circ} 40^{\prime} 0^{\prime \prime}-6^{\circ} 0^{\prime}$ 0" Lintang Selatan dan $103^{\circ} 30^{\prime} 0^{\prime \prime}-104^{\circ}$ 50' 0" Bujur Timur (uun-halimah. blogspot.co.id).

Penduduk Kabupaten Pesisir Barat berjumlah 144.763 jiwa, dengan jumlah Kepala Keluarga (KK) 33.292. Jika dilihat berdasarkan jenis kelaminnya, maka jumlah penduduk laki-lakinya mencapai 76.240 jiwa dan penduduk berjenis kelamin perempuan mencapai 68.523 jiwa. Para penduduk ini tersebar di 11 kecamatan, yaitu Pesisir Selatan dihuni oleh 21.762 jiwa $(5,09 \%)$, Bengkunat dihuni oleh 7.620 jiwa $(5,61 \%)$, Bengkunat Belimbing 24.009 jiwa $(5,61 \%)$, Ngambur
17.953 jiwa 4,20\%, Pesisir Tengah 18.358 jiwa (4,29\%), Karya Penggawa 14.292 jiwa (3,34\%), Way Krui 8.328 jiwa 1,95\%, Krui Selatan 8.531 jiwa 1,99\%, Pesisir Utara 8.202 jiwa $1,92 \%$, Lemong 14.365 jiwa 3,36\%, dan Pulau Pisang dihuni oleh 1.343 jiwa $(0,31 \%)$. Sementara jika dilihat berdasarkan golongan usia, maka penduduk yang berusia 0-14 tahun ada 54.825 jiwa $(34,44 \%)$, kemudian yang berusia 15-54 tahun ada 76.632 jiwa $(50,83 \%)$, dan yang berusia 55 tahun ke atas 12.559 jiwa (14,73\%). Golongan umur tersebut secara rinci dapat dilihat pada tabel di bawah ini.

Tabel 1. Penduduk Pesisir Barat Berdasarkan Golongan Umur

\begin{tabular}{|c|c|c|c|}
\hline No & Gol Umur & Jumlah & Prosentase \\
\hline 1. & $0-4$ & 18.784 & 12,98 \\
\hline 2. & $5-9$ & 19.830 & 13,70 \\
\hline 3. & $10-14$ & 16.211 & 11,20 \\
\hline 4. & $15-19$ & 12.190 & 8,42 \\
\hline 5. & $20-24$ & 10.234 & 7,07 \\
\hline 6. & $25-29$ & 10.883 & 7,52 \\
\hline 7. & $30-34$ & 10.874 & 7,51 \\
\hline 8. & $35-39$ & 9.742 & 6,73 \\
\hline 9. & $40-44$ & 8.558 & 5,91 \\
\hline 10. & $45-49$ & 7.788 & 5,38 \\
\hline 11. & $50-54$ & 6.363 & 4,40 \\
\hline 12. & $55-59$ & 4.596 & 3,17 \\
\hline 13. & $60-64$ & 3.213 & 2,22 \\
\hline 14. & $65-69$ & 2.267 & 1,57 \\
\hline \multirow[t]{2}{*}{15.} & 70-ke atas & 2.183 & 1,51 \\
\hline & & 144.763 & 100,00 \\
\hline
\end{tabular}

Sumber: (BPS Kabupaten Lampung Barat, 2013)

Pola pemukiman penduduk Pesisir Barat umumnya perumahan berada di sekitar jalan, baik itu jalan kabupaten, kecamatan, maupun desa, berjajar, dengan arah menghadap ke jalan (pola pita/ribbon). Arah rumah yang berada bukan di pinggir jalan pun arahnya mengikuti yang ada di pinggir jalan. Sebagian besar rumah tersebut masih berbentuk tradisional yang mengelompok dan tersebar secara sporadis. Adapun cirinya berupa bangunan semi permanen berbentuk panggung, menggunakan sumur 
(air tanah) sebagai sumber air minum, dan kurang atau belum mendapat pasokan listrik. Khusus untuk pasokan listrik, kabupaten baru ini relatif masih kurang. Oleh karena itu, tidak mengherankan apabila sering terjadi pemadaman listrik secara bergilir. Bahkan, pemadaman hampir terjadi setiap hari dengan jangka waktu antara beberapa jam hingga beberapa hari. Untuk mensiasatinya hampir di setiap rumah memasang genset berbahan bakar solar agar tetap menikmati listrik.

Letak Kabupaten Pesisir Barat yang relatif jauh dari ibukota provinsi (Bandarlampung) membuat perekonomian mayoritas penduduknya masih mengandalkan sektor pertanian untuk memenuhi kebutuhan hidup. Menurut data dari BPS Lampung Barat (Kabupaten Induk) tahun 2013, aktivitas perekonomian mencapai 2,9 triliun yang dibagi menjadi beberapa kategori lapangan usaha, yaitu: pertanian, kehutanan dan perikanan 52,90\%; pertambangan dan penggalian $5,15 \%$; industri pengolahan $5,37 \%$; pengadaan air, pengelolaan sampah, limbah dan daur ulang 0,06\%; konstruksi $5,09 \%$; perdagangan besar/eceran, reparasi mobil, dan sepeda motor 11,23\%; transportasi dan pergudangan 0,9\%; penyedia akomodasi dan makan minum 1,55\%; informasi dan komunikasi 1,56\%; jasa keuangan dan asuransi 1,64\%; real estate $3,55 \%$; jasa perumahan $0.14 \%$; dan administrasi pemerintahan, pertanahan dan jaminan sosial $5,17 \%$.

\section{Struktur Masyarakat Pesisir Barat}

Masyarakat Pesisir Barat merupakan pendukung adat Saibatin (Peminggir) yang umumnya bertempat tinggal di sekitar pantai, mulai dari Krui hingga Kayu Agung (Harsono, 2013:246). Sebagai sebuah kesatuan sosial, mereka mempunyai struktur tersendiri yang tercermin dalam kelas-kelas sosial yang ditentukan berdasarkan asal usul serta hubungan kekerabatan. Struktur tersebut dipertahankan dari satu generasi ke generasi berikutnya dalam bentuk mitosmitos sebagai perwujudan keyakinan yang berkembang menjadi identitas kelompok (Rudito, 2013:3). Menurut mitos tentang asal usul, orang Pesisir Barat berkeyakinan bahwa mereka berasal dari keturunan Kepaksian Skala Brak/Sekala Beghak yang lokasinya berada di kawasan lereng Gunung Pesagi (sekarang di sekitar Kabupaten Lampung Barat). Sebelum menjadi kepaksian, menurut Masduki (2006: 23-25), pada abad 15 datang empat kelompok masyarakat yang menduduki sekitar Danau Ranau. Di sebelah barat danau dihuni orang-orang yang datang dari Pagaruyung Sumatera Barat pimpinan Dipati Alam Padang. Di sisi timur danau, kelompok orang-orang Sekala Beghak yang dipimpin Pangeran Liang Batu dan Pahlawan Sawangan (berasal dari Kepaksian Nyekhupa) serta kelompok yang dipimpin Raja Singa Jukhu (dari Kepaksian Bejalan Di Way). Sementara kelompok terakhir menempati sisi utara danau yang dipimpin Umpu Sijadi Helau yang juga dari Sekala Beghak.

Mereka kemudian berbaur dan membentuk sebuah persekutuan buway (keturunan) bernama Kepaksian Sekala Baghak dan membaginya menjadi empat marga atau kebuayan, yaitu: (1) Umpu Bejalan Di Way memerintah daerah Kembahang dan Balik Bukit dengan Ibu Negeri Puncak, daerah ini disebut dengan Paksi Bejalan Di Way; (2) Umpu Belunguh memerintah daerah Belalau dengan Ibu Negerinya Kenali, daerah ini disebut dengan Paksi Buay Belunguh; (3) Umpu Nyerupa memerintah daerah Sukau dengan Ibu Negeri Tapak Siring, daerah ini disebut dengan Paksi Buay Nyerupa; dan (4) Umpu Pernong memerintah daerah Batu Brak dengan Ibu Negeri Hanibung, daerah ini disebut dengan Paksi Buay Pernong.

Keempat paksi tersebut mengutus lima orang penggawanya (Raja Penyukang Alam, Raja Panglima, Raja Nurakdim, Raja Belang, dan Nungkah Nungkeh Dego Pemasok Rulah) untuk membantu Lumia 
Ralang Pantang dari Pantau Kota Besi yang masih keturunan Pangeran Tanah Jaya dari daerah Banten (Imron, 2014). Bersama-sama mereka menumpas sukubangsa Tumi yang tinggal di sekitar wilayah Pesisir Barat. Setelah berhasil ditaklukkan kelima penggawa bersepakat mendirikan kerajaan yang diberi nama Penggawa Lima di bekas wilayah orang Tumi. Masing-masing menempati wilayah yang telah disepakai bersama. Raja Penyukang Alam bersama marga-marga yang dinaunginya menempati wilayah Cukuh Mersa (Bandar), Raja Panglima menempati wilayah Pekon Teba (Perpasan), Raja Nurakdim menempati wilayah Pematang Gedung (Pekon Balak Laay), Raja Belang menempat wilayah Pematang Gedung (Pekon Laay), dan Raja Nungkah Nungkeh Dego Pemasok Rulah menempati wilayah Pagar Dewa (Imron, 2014).

Pada masa kekuasaan Inggris, wilayah pesisir barat Lampung menjadi salah satu Onderafdelling dalam wilayah administrasi Regenschap (Karesidenan) Bengkulu. Sebagai konsekuensinya, struktur kekuasaan lokal berada di bawah Onderafdeling melalui Inlandsche Gemeent Ordonantie Buitengewestan (peraturan dasar mengenai pemerintahan desa) (Imron, 2014). Menurut Masduki (2006: 27) pada masa ini kekuasaan marga-marga Penggawa Lima dan kebuayan Sekala Bekhak dipecah menjadi: (1) Bukti-bukti terdiri atas Marga Sukau, Marga Liwa, Marga Kembahang, Marga Batu Brak, Marga Kenali, Marga Suoh, Marga Way Tenong; (2) Krui Utara terdiri atas Marga Pulau Pisang, Marga Pugung Tampak, Marga Pugung Penengahan, Marga Pugung Malaya; (3) Krui Tengah terdiri atas Marga Way Sindi, Marga Laay, Marga Bandar, Marga Pedada, Marga Ulu Krui, Marga Pasar Krui, Marga Way Napal; dan (4) Krui Selatan terdiri atas Marga Tenumbang, Marga Ngambur, Marga Ngaras, Marga Bengkunat, Marga Belimbing.
Perkembangan selanjutnya, kebuayan Paksi Sekala Beghak menjadi enam, yaitu: Belunguh (Kenali), Pernong (Batu Brak), Bejalan Di Way (Kembahang), Nyerupa (Sukau), Bulan/Nerima (Lenggiring), dan Buay Menyata/Anak Mentuha (Luas). Namun, dari enam kebuayan tersebut hanya empat yang menjadi Raja. Dua buay yang tidak memerintah adalah Buay Menyata/Anak Mentuha dan Buay Bulan/Nerima. Buay Menyata yang merupakan penghuni pertama Kerajaan Skala Brak diangkat sebagai Anak Mentuha atau yang dihormati, sedangkan Buay Nerima merupakan Nakbar/Mirul (anak perempuan yang diambil orang).

Saat ini, berdasarkan SK Gubernur Lampung No. G/362/B.II/HK/1996, wilayah adat marga-marga di wilayah Pesisir memiliki batas yang cukup jelas. Masing-masing marga dipimpin oleh seorang kepala marga dan memiliki tujuh tingkatan Gelar yaitu: Suntan, Raja, Batin, Radin, Minak, Kimas dan Mas. Adapun nama-nama Marga di Wilayah Pesisir di Kabupaten Pesisir Barat Lampung yakni: Belimbing Bandar Dalam Bengkunat, Bengkunat Sukamarga Bengkunat, Ngaras Negeri Ratu Ngaras Bengkunat, Ngambur Negeri Ratu Ngambur Pesisir Selatan, Tenumbang Negeri Ratu Tenumbang Pesisir Selatan, Way Napal Way Napal Pesisir Tengah, Pasar Krui Krui Pesisir Tengah, Ulu Krui Gunung Kemala Pesisir Tengah, Pedada (Penggawa V Ilir) Pedada Pesisir Tengah, Bandar (Penggawa V Tengah) Bandar Pesisir Tengah, Laay (Penggawa V Ulu) Laay Karya Penggawa, Way Sindi Karya Penggawa, Pulau Pisang Pesisir Utara, Pugung Tampak Pesisir Utara, Pugung Penengahan Lemong, dan Pugung Malaya Lemong.

\section{Sistem Kekerabatan dan Ideologi Patriarki}

Sistem kekerabatan memiliki peranan penting untuk menggambarkan struktur sosial masyarakat. Menurut Lowie, sebagaimana yang dikutip oleh 
Hermaliza (2011:124), kekerabatan adalah hubungan-hubungan sosial melalui jalur genealogis dan atau perkawinan yang terjadi antara seseorang dengan saudarasaudaranya atau keluarganya (baik keluarga inti maupun luas). Lebih lanjut, interaksi antarkerabat berdasarkan peran dan statusnya masing-masing membentuk sebuah sistem yang meliputi istilah kekerabatan, keluarga inti, peran dan fungsi anggota keluarga, keluarga luas, dan peran dalam tatanan adat.

Sistem kekerabatan dalam suatu masyarakat dapat berbentuk unilineal, bilateral, dan sistem keturunan ganda. Menurut Koentjaraningrat (1985: 129-130) sistem kekerabatan matrilineal bersama dengan patrilineal termasuk ke dalam sistem kekerabatan yang menetapkan garis keturunan berdasarkan satu garis atau unilineal. Dalam sistem kekerabatan matrilineal menghitung hubungan kekerabatan melalui garis perempuan sementara sistem kekerabatan patrilineal menetapkan garis keturunan menurut ayah atau laki-laki. Sistem kekerabatan lainnya adalah sistem kekerabatan non unilineal yaitu bilineal dan bilateral. Sistem kekerabatan bilineal menghitung hubungan kekerabatan melalui laki-laki saja untuk sejumlah hak dan kewajiban tertentu dan melalui perempuan saja untuk sejumlah hak dan kewajiban tertentu pula. Sedangkan sistem kekerabatan bilateral menghitung hubungan kekerabatan melalui laki-laki maupun perempuan.

Pada masyarakat adat Saibatin di Pesisir Barat sistem kekerabatannya ditarik secara patrilineal mulai dari asal usul mereka. Adapun penerapannya bersifat primogenitur, yaitu bahwa harta pusaka berupa rumah, pekarangan, sawah dan atau ladang serta seluruh harta kekayaan sebuah keluarga hanya akan diwariskan pada anak laki-laki tertua (sulung). Dengan demikian harta pusaka tidak pecah terbagi-bagi. Anak laki-laki lainnya tidak mendapat warisan dan apabila tetap tinggal di desa sebagai petani, hanya sebagai penggarap tanah pusaka yang dikuasai oleh kakak laki-laki tertua (Imron, 2014).

Aturan kekerabatan yang bersifat patrilineal-primogenitur dianut seluruh marga yang membangun buay dan kepaksian di Pesisir Barat. Oleh karena itu, dalam setiap marga kedudukan adat tertinggi berada pada anak laki-laki tertua dari keturunan tertua yang disebut Penyimbang. Seseorang yang memperoleh gelar dan status sebagai penyimbang marga akan sangat dihormati dalam masyarakatnya karena menjadi penentu dalam setiap proses pengambilan keputusan adat. Sementara kesatuan hidup masyarakatnya tercermin dalam ikatan kekerabatan yang menganut sistem keluarga luas (extended family). Ikatan kekerabatan didasarkan pada hubungan keturunan (ikatan darah), ikatan perkawinan, ikatan mewarei (pengangkatan saudara), dan ikatan berdasarkan pengangkatan anak.

Kontruksi sosial berdasar hubungan patrilineal ini mengarah pada dominasi kekuasaan laki-laki atau Patriarki. Menurut Wably sebagaimana yang dikutip oleh Wiyatmi (2015:7), patriarki adalah sebuah sistem dari struktur sosial yang menempatkan laki-laki dalam posisi dominan, menindas, dan mengeksploitasi perempuan. Patriarki muncul sebagai bentuk kepercayaan atau ideologi yang menempatkan kedudukan laki-laki lebih tinggi dibanding perempuan melalui lembaga-lembaga sosial, politik, dan ekonomi.

Kultur patriarki di Kepaksian Sekala Beghak mempengaruhi struktur sosial masyarakatnya, mulai dari level paling tinggi (Kepaksian) hingga ke level terendah yaitu keluarga. Dalam kehidupan rumah tangga misalnya, laki-laki ditempatkan sebagai pusat kekuasaan. Bila berasal dari kalangan bangsawan, maka dialah yang berhak mewarisi gelar kebangsawanan ayahnya. Bila dia berasal dari kalangan kebanyakan, dia berhak meneruskan garis keturunannya kepada anak-anaknya. Sebagai pusat kekuasaan, 
laki-laki memiliki kuasa untuk mengambil keputusan dalam kerumahtanggaan. Ia digambarkan sebagai orang yang kuat, jantan, berani, bersifat pelindung, pantang menyerah dan rasional. Sementara perempuan dicitrakan sebagai lemah lembut, emosional, dan selalu mengandalkan insting sehingga ditempatkan pada posisi subordinasi yang hanya berkiprah di sektor domestik.

Berdasarkan konstruksi sosial di atas, Herwanto (2012), menyatakan bahwa orang tua cenderung memberi kebebasan pada anak laki-lakinya untuk melakukan aktivitas di luar rumah, baik siang maupun malam hari serta kegiatan yang cenderung mengukuhkan sifat kelaki-lakiannya sehingga memungkinkan anak laki-laki secara fisiologi, sosiologis maupun psikologis tumbuh sebagai pribadi yang kuat dan mandiri. Sedangkan terhadap anak perempuan cenderung mendiskriminasikan dengan memberi pembelajaran yang berkenaan dengan peran domestiknya untuk menyelesaikan pekerjaan di lingkungan rumah tangga saja.

Pembedaan kewajiban dan hak antara kedua gender itu melahirkan ketidakadilan terhadap kaum perempuan dalam melakukan kegiatan sosial, ekonomi, politik, maupun budaya. Manifestasinya tercermin dalam berbagai bentuk ketidakadilan, marginalisasi, dan subrodinasi peran yang merugikan perempuan. Namun karena telah berlangsung sejak lama, maka dianggap sebagai suatu kebiasaan turun-temurun dan tidak dipersoalkan lagi sebagai tindakan ketidakadilan dan subordinasi gender. Posisi subordiasi ini diterima sebagai ketentuan adat yang harus ditaati, tetapi di dalam diri sebagian perempuan timbul suatu "perlawanan". Salah satu bentuknya adalah muncul tradisi tutur hahiwang.

\section{Hahiwang}

\section{a. Struktur Hahiwang}

Sebagaimana disebutkan di atas, hahiwang merupakan satu dari beberapa ragam karya sastra tutur masyarakat Lampung, khususnya masyarakat 16 Marga Pesisir Krui. Hahiwang umumnya dilantunkan oleh kaum perempuan sebagai ungkapan perasaan jiwa atas situasi yang dihadapinya dalam lantunan khas yang menyayat hati. Adapun struktur hahiwang yang dilantunan itu sama seperti setiap puisi tradisional lainnya yang terikat oleh bentuk dan isi. Dalam hahiwang bentuknya terdiri atas bait-bait yang bersajak. Sebuah bait secara tradisional dibangun oleh sejumlah baris dan pola-pola sajak pada setiap akhir larik. Banyaknya jumlah baris pada setiap bait sangat bergantung pada kemampuan seorang dalam mengungkapkan ekspresi jiwanya.

Penelaahan pada sejumlah hahiwang diperoleh petunjuk (1) pola sajak akhir tidak harus sama; bisa saja bait pertama mempunyai pola sajak akhir a-ba-b-a-b, sedangkan bait kedua berpola c-dc-d-c-d; dan (2) Jumlah baris pada setiap bait tidak selalu sama. Ada yang berjumlah enam baris setiap baitnya, ada pula yang delapan baris atau empat baris. Berikut contoh hahiwang yang berjumlah 4 baris dengan pola sajak a-b-a-b.

\section{Sakik sikam ji nimbang \\ Kak kapan ago segai \\ Hiwang ni sanak malang \\ Sikal kilu mahap pai}

Hgatong mangedok sai di usung

Ya gila sanak aghuk

Apak ni saka lijung

Sisi di tinggal induk

Mangedok daya lagi

Sikam ghatong jak bungkuk

Nyeghahko jama kuti

Tabikpun di puskam kaunyinna,

kalau ya keteghima

Lain mak ngaku gila

Kindang payu juga mu

Ajo ku kak dia

Mak santor pengandanmu 
Mula kunduh katinuh

Seno sai nyak mak nyakak

Mak nambak ku kintu luh

Kak niku mak ku liak

\section{Lain ki basi bacakh \\ Wat aga ti rancaka \\ Nyak ku jak nengiis kabakh \\ Daleh ti tengan diya}

Way ni uma dunggak ni atakh

Sanak pungaji cawa

Kintu ya mak muhellakh

Masa do niku muba

Sumber: Mardiah, (61 tahun), Sandaran Agung Penggawa 5 Krui, Lampung Pesisir.

Baris atau larik pada hahiwang tidak memiliki sampiran. Semua baris mengandung isi. Tidak ada larik yang mengandung kata atau kalimat samarsamar. Oleh karena itu, mudah dipahami apabila isi hahiwang dapat berbentuk cerita yang terdiri atas puluhun bait/tidak terbatas. Penulis memiliki kebebasan untuk mencurahkan ide, ekspresi jiwa dan pandangannya sesuai dengan keperluannya. Hal ini pula menjadi petunjuk bahwa hahiwang merupakan "tuturan bercerita", tuturan yang memiliki cerita tertentu.

Pemakaian sebuah bait dalam 2 (dua) baris sebagaimana ditunjukkan data di atas dapat dijelaskan sebagai berikut. Pertama, tidak semua bentuk hahiwang memakainya. Kedua, peletakan bait 2 baris terpola pada bagian awal dan akhir atau pada pergantian bahasan. Pemakaian pada bagian awal digunakan sebagai salam pembukaan dan pada akhir digunakan sebagai penutup cerita. Adapun di tengah berfungsi sebagai jeda atau pengalihan bahasan. Ketiga, berfungsi penyingkat cerita semacam pantun kilat dalam sastra Melayu.

Untuk lebih jelasnya, berikut adalah beberapa contoh hahiwang.
Badan Siji sai ghayang

Lain nyak kurang mengan

Ngegham semanjang-manjang

Guwai neghasa badan

Nengah bingi nyak miweng

Ngipi gham setunggaan

Ati ngelaruh mulang

Kakak di perantauan

Ya Allah tulung babang

Ngadapi garis tangan

Jarak pulau nyeberang

Jejama seandanan

Kira kak dapat mulang

Kapan gham setunggaan

Ngesaikan pilih tunang

Wa ati sai tujuwan

Diri ku ngambang-kambang

Debingi ngegabah bulan

Kakak ku bayang-bayang

Kunah di lam lamunan

Hahiwang di atas bercerita tentang ratapan hati para perempuan. Hahiwang pertama berkisah tentang perempuan yang ditinggal pergi oleh suaminya. Sang suami pergi merantau mencari kerja hingga ke Pulau Jawa dan berjanji setelah berhasil akan segera pulang ke kampung halaman. Namun, janji hanya tinggal janji. Setelah ditunggu sekian lama suami tidak kunjung pulang. Dia hanya dapat meratapi nasib dan tidak dapat berbuat apa-apa selain menunggu Sang suami pulang.

Sumber: Mardiah, (61 tahun), Sandaran Agung Penggawa 5 Krui, Lampung Pesisir.

Minyak khum ni minyak khum

Tebeli di Pulau Pisang

Asalamualaikum

Skinda nyembuka

Ajo ngebuka kisah

Kisah ni Bebai Ganding

Lamon sai bugindah

Tilaju muneh pusing

Ngegetas ditekhatas 
Siwok campokh sajekhu

Lamon muli sai ngusung tas

Mikhat ti ucak gukhu

Ngedekhing kuol mangking

Halipu sakik tengah

Anjak di khok angging

Mikudo sai kupenah

Apisai nyining sining

Mendikha ampai mesak

Khadu saka nyak gekhing

Kidang mak kuawa ngucak

Bukhung nyalai di hatok

Makdacok nginong kayu

Sabah jawoh makmirok

Pekhulang nyak ulihmu

Tekhuk mid suoh

Kidang cakak pekharu

Tekhoknya munggak medoh

Duaan jama niku

Bejukung patoh dayung

Belabuh di kuala

Mulang nyaku mik Lampung

Merantau mak dok kerja

Nutuk tian mik pugung

Nebukak pulan rimba

Nanom kupi rek tiyung

Tiselang muneh lada

Kupi muakni ngagung

Bang dialau ko papi'a

Tisuah muneh anjung

Delom ni kupi rek lada

Jak miwang tumpak lalang

Kelitah jak sekeli

Najin kuti masenang

Dang lupa dipuari

Kipak kham tungga ralang

Dang lupa jak lom hati

Kipak pokon kham sumang

Dang putus siratu rohmi

Ibarat ramji tandang

Pagun mak munsa huwi
Biluk ram laju mulang

Tikekoh dibi khani

Najin gumah tisandang

Nekham huhik dibumi

Dang sedih daleh miwang

Tiwewah kon hati

Banjer muneh way kunjer

Iwani mak ngedok lagi

Hahap ni Lampung pesisir

Haga wat do majuni

Taru pai antak ija

Karangngani mak lagi

Kitubang salah cawa

Ampun beribu kali

Pelepai betik sapai

Di dwakha tambulek

Wayak ji antak ija pai

Nanti tisambung muneh

Hahiwang di atas berkisah tentang perempuan yang akan menikah. Sebagai bagian dari masyarakat Saibatin yang patrilineal dan beradat menetap patrilokal, setelah menikah dia akan tinggal di lingkungan kerabat suaminya. Selain itu, dia juga harus melepas status sebagai bagian dari marga orang tua karena akan mengikuti marga suami. Oleh karenanya, sebelum menikah dia berhahiwang mengungkapkan kesedihan hati sekaligus salam perpisahan kepada para perempuan di rumahnya (nenek, ibu, bibi, dan kaum kerabat lain) secara satu persatu mulai tengah malam hingga adzan subuh berkumandang.

Sumber: Lakma Dewi, (54 tahun), Sandaran Agung Penggawa 5 Krui, Lampung Pesisir

\section{Hahiwang dan Dominasi Patriarki \\ a. Hahiwang sebagai Ungkapan Ketidakberdayaan Perempuan}

Beberapa hahiwang di atas merupakan ungkapan perempuan atas problematika ketimpangan yang mengarah pada ketidakadilan gender. Gender yang 
oleh Mansour Fakih (1997:7) didefinisikan sebagai suatu sifat yang melekat pada kaum laki-laki dan perempuan yang dikonstruksi secara sosial maupun kultural, dalam masyarakat 16 marga Pesisir Krui digunakan untuk membedakan hak dan kewajiban dalam melakukan kegiatan sosial, ekonomi, politik, maupun budaya. Perbedaan peran berdasar gender ini terjadi melalui proses sosialisasi normanorma kultural dan keagamaan yang lama dan sangat panjang sehingga seolah-olah telah menjadi kodrat Ilahi.

Bagi perempuan Saibatin Krui, mulai dari masa kanak-kanak telah disosialisasikan berbagai macam nilai dan norma yang dibentuk oleh budaya patriarki, baik oleh keluarganya sendiri (terutama pihak ibu) maupun lingkungan di sekitarnya (kerabat dan para tetangganya) dengan tujuan agar dapat berinteraksi dengan lingkungan komunitasnya. Bentuk sosialisasi yang dilakukan adalah pembelajaran yang berkenaan dengan peran perempuan dalam menyelesaikan urusan domestik saja. Selain itu, anak perempuan juga dibentuk sedemikian rupa dengan tidak diberi ruang atau keleluasaan berada di sektor publik, sesuai dengan kehendak budaya masyarakat maupun ajaran agamanya.

Hasil sosialisasi konstruksi sosial tentang gender ini mempengaruhi perkembangan kondisi fisik dan psikis kaum perempuan. Mereka menjadi pribadi yang kurang berani, penurut, rajin, lemah, emosional, dan selalu meminta dilindungi. Akibatnya kehidupan perempuan menjadi sangat dependen pada laki-laki yang dianggap mempunyai posisi lebih tinggi. Laki-laki memanfaatkan kebergantungan ini untuk mengekalkan kekuasaannya dalam bidang politik, sosial, ekonomi, dan budaya. Akibatnya timbul berbagai bentuk ketidakadilan, marginalisasi, dan subrodinasi peran yang merugikan perempuan.

Salah satu bentuk ketidakadilan gender tersebut berkaitan dengan pranata perkawinan. Masyarakat Saibatin di Pesisir
Barat menganut sistem perkawinan yang mengutamakan jalur lineage atau keturunan yang saling berkaitan dari nenek moyang yang sama (Masduki, 2006:65). Selain itu, perkawinan juga bersifat patrilineal dengan adat menetap patrilokal. Setelah menikah seorang perempuan harus masuk dalam marga dan tinggal di lingkungan keluarga suaminya (mengiyan). Melalui mas kawin atau yang lebih dikenal dengan sistem dowry yang nominalnya antara puluhan hingga ratusan juta rupiah, perempuan "diambil" oleh kerabat suami untuk dijadikan sebagai aset tenaga kerja. Konsekuensinya, perempuan harus keluar dari keluarganya sendiri dan memaksanya menjadi "pelayan" laki-laki. Dia menjadi tidak berdaya dan teralineasi karena seluruh aktivitas hidupnya hanya merupakan kelengkapan bagi orang lain.

Ketidakberdayaan perempuan untuk mengkaunter dominasi laki-laki disiasati dengan membangun aktivitasaktivitas tertentu sebagai pengibur diri. Hahiwang merupakan salah satu bentuknya. Apabila dihayati lantunannya dipenuhi rasa kesedihan yang mencerminkan kenestapaan hati. Hal itu mengindikasikan penderitaan seseorang terhadap satu hal. Seorang informan menceritakan pengalaman hidupnya saat menikah dahulu. Ia demikian galau, sedih yang teramat mendalam. Terbayang dalam benak pikirannya akan berpisah dengan sanak keluarganya. Malam hari sebelum pernikahan, ia mendatangi sanak keluarga terdekatnya untuk menyampaikan salam perpisahan. Semalaman menangis, bercucur air mata menyalami satu persatu kerabatnya sambil berhahiwang.

Seiring waktu hahiwang tidak hanya digunakan saat masa peralihan saja, melainkan juga ke segala aspek yang membentuk pencitraan inferioritas pada diri perempuan. Misalnya, ketika seorang perempuan kawin dengan "Bang Toyib" yang jarang pulang, atau ketika sang suami jarang menafkahi (lahir-batin), ia akan berhahiwang juga. Oleh karena sifatnya yang sangat personal, hahiwang biasanya 
disenandungkan seorang diri tatkala sedang mengerjakan sesuatu hal di dalam rumah atau di kebun. Adapun tujuannya hanya sebagai ratapan yang diperuntukkan bagi diri sendiri. Sebab, perempuan yang telah tersubordinasi oleh konstruksi adat patriarkis cenderung memilih bungkam dan tidak akan melalukan perlawanan. Dia tetap akan berperan sebagai fixer dan pleaser untuk menjaga hubungannya tetap stabil, harmonis, dan menyenangkan. Selain itu, dia juga akan tetap mencoba sebagai martyr untuk memenuhi harapan pasangannya walau harus mengorbankan diri.

\section{b. Hahiwang sebagai Sebuah Kesenian}

Dalam perkembangannya saat ini, hahiwang telah mengalami pergeseran fungsi. Ia tidak lagi sebatas "kepentingan pribadi" dalam upaya melepas kegundahan hati. Hahiwang juga difungsikan sebagai kesenian pelengkap acara muda-mudi (nyambai, miyah damagh, kedayek), hiburan pengisi waktu luang, media dakwah, penyampai nasihat kepada masyarakat, peningkat apresiasi masyarakat terhadap kesenian daerah (Sanusi, 2001:109), senandung pada saat menidurkan anak, hingga penarik simpatisan dalam Pemilukada.

Perkembangan fungsi tersebut tidak terlepas dari kungkungan budaya patriarki. Para lelaki yang merasa tertarik mendengar lantunan hahiwang, bukan menjadikannya sebagai ajang introspeksi diri agar lebih baik dalam memposisikan kaum perempuan. Mereka malah "memaksa" para perempuan pelantun membuat hahiwang sesuai dengan maksud dan tujuannya masing-masing. Apabila difungsikan sebagai pelengkap dalam upacara adat, pelantun akan membuat teks hahiwang yang sesuai dengan maksud dan tujuan upacara. Apabila digunakan sebagai media dakwah, pelantun diharuskan membuat teks hahiwang yang berkaitan dengan keagamaan, seperti: ketauhidan, imbauan beribadah atau kisah-kisah para nabi. Sedangkan bila dijadikan sebagai penarik simpatisan dalam Pemilukada, pelantun membuat teks hahiwang yang berkenaan dengan kondisi daerah serta calon wakil rakyat yang memesan hahiwang.

Struktur dan bahasan hahiwang pun tidak lagi sesuka hati, melainkan memiliki pola umum seperti pada penulisan bentuk sastra tradisional. Pola umum tersebut diawali dengan pembukaan (salam penghormatan pada para pendengar, maksud dan tujuan pelantunan), kemudian isi atau kandungan yang bergantung pada pesanan atau acara yang sedang diikuti, dan diakhiri dengan penutup berupa harapan pelantun, permintaan maaf, serta salam.

Dalam konteks ini, teks hahiwang telah bergeser fungsi dari ratapan diri menjadi sebuah kesenian. Isinya pun tidak lagi sebatas "kepentingan pribadi" dalam upaya melepas kegundahan hati, melainkan telah berkembang ke arah lingkungan sosial yang lebih luas, bergantung dari situasi dan kondisi ketika dilantunkan. Berdasarkan fungsinya tersebut Kurnia (2010) mengkategorikan hahiwang menjadi tiga, yaitu: hahiwang kesedihan, hahiwang agama, dan hahiwang adat. Hahiwang kesedihan tidak hanya berupa ekspresi kesedihan dalam hidup berumah tangga, tetapi juga tanggapan terhadap kerusakan lingkungan. Hahiwang agama menceritakan hal-hal seputar syariat (hukum-hukum Islam), rukun iman, rukun Islam, peristiwa Isra Miraj, aturan membaca dalam Al Quran, perjuangan para nabi, dan lain sebagainya yang berhubungan dengan agama Islam. Sedangkan hahiwang adat berisi tentang silsilah keturunan suatu keluarga atau pesan-pesan khusus bagi pasangan yang menikah. Hahiwang adat umumnya dikumandangkan pada acara-acara adat (perkawinan, pemberian gelar adat, nyambai, dan lain sebagainya).

Dominasi laki-laki tidak hanya dalam bentuk "perintah" membuat lirik yang tidak lagi bersifat personal. Bahkan ada beberapa di antara mereka yang ikut 
terjun menjadi pelantun hahiwang. Namun tidak semua orang sanggup melantunkannya karena hahiwang memiliki gaya dan irama atau cengkok khas yang relatif sukar dipelajari. Hanya para seniman yang telah terbiasa bergelut dengan seni tradisi yang dapat membuat teks sekaligus melantunkannya.

Salah seorang di antaranya adalah Mursi $\mathrm{M}$ atau lebih dikenal dengan nama panggung Mamak Lawok. Dia adalah seniman tradisi yang biasa membawakan segata, bebandung, ringget, wayak/muayak dan hahaddo yang berirama mirip seperti hahiwang. Mamak Lawoklah yang mengembangkan hahiwang agama dan adat dengan cara menampilkan di setiap acara begawi yang dihadirinya. Hahiwangnya tidak berupa ekspresi kesedihan mengenai pengalaman hidup, melainkan menembus ranah adat istiadat dan keagamaan.

Penghilangan unsur ratapan ini berkaitan dengan konstruksi budaya patriarki yang mencitrakan bahwa laki-laki haruslah memiliki sifat pemberani, kuat, agresif, mandiri, cekatan, pantang menyerah yang menjadikannya terlatih dan termotivasi mempertahankan sifat tersebut. Hahiwang yang berarti ratapan hati hanya ada dalam konstruksi gender perempuan Saibatin yang dicitrakan sebagai lemah lembut, emosional, penakut, penurut, serta keibuan. Oleh karena itu, teks hahiwang yang dibuat oleh Mamak Lawok atau seniman laki-laki di Pesisir Barat umumnya berisi tentang petuah-petuah adat dan aturan-aturan yang berlaku dalam agama Islam. Yang penting adalah nada, irama, dan suara pekau yang khas hahiwang sehingga membuat pendengar tersentuh hati bila mendengarnya.

\section{c. Pewarisan Hahiwang dalam Budaya Patriarki}

Dalam hal pewarisan hahiwang pun budaya patriarki tetap berperan. Seorang informan menyatakan bahwa dia sulit mengajarkan hahiwang kepada anakanak yang berada di sekitar tempat tinggalnya. Adapun penyebabnya tidak hanya karena relatif sulit mempelajari seni tradisi hahiwang, tetapi juga oleh stratifikasi sosial masyarakat adat Saibatin Krui. Dalam proses regenerasi seseorang yang ingin belajar hahiwang harus mampu menciptakan bait-bait terdiri dari 3-6 baris yang membentuk rangkaian cerita atau kisah. Selain itu, juga mampu melantunkannya menjadi sebuah tembang yang memiliki cengkok-cengkok tertentu sehingga terdengar memilukan dan menyayat hari. Oleh karena itu, untuk mempelajarinya tentu membutuhkan waktu yang relatif lama.

Perempuan pelantun hahiwang yang sudah mahir dan ingin menularkan ilmunya kepada orang lain tidak dapat begitu saja melaksanakan niatnya. Dia harus melihat statusnya dalam masyarakat yang mempunyai struktur tersendiri yang tercermin dalam kelas-kelas sosial yang ditentukan berdasarkan asal usul serta hubungan kekerabatan. Masyarakat adat Saibatin di Pesisir Barat membagi diri menjadi 16 marga. Masing-masing marga dipimpin oleh seorang Saibatin (Kepala Marga) dan memiliki tujuh tingkatan Gelar yaitu: Suntan, Raja, Batin, Radin, Minak, Kimas dan Mas.

Struktur sosial berdasarkan
tingkatan gelar adat mempengaruhi ruang gerak masyarakat, mulai dari level paling tinggi (Kepaksian) hingga ke level terendah yaitu keluarga. Atau dengan kata lain, terdapat ramburambu tertentu yang mengatur hubungan antarstatus dalam kehidupan sehari-hari. Seseorang tidak dapat sesuka hati berhubungan tanpa mengindahkan statusnya karena akan mendapat sanksisanksi tertentu (adat maupun sosial) apabila melanggarnya.

Apabila pelantun hahiwang berada dalam keluarga berstatus atau bergelar Minak misalnya, dia akan relatif mudah menggerakkan anak-anak dari keluarga yang berstatus di bawahnya (Kimas dan Mas) untuk belajar hahiwang. Namun, sulit "memaksa" anak-anak dari keluarga 
berstatus Radin, Batin, Raja, apalagi Suntan tanpa persetujuan orang tua mereka. Apabila orang tua menyetujui, dalam menentukan jadwal latih pun tidak dapat begitu saja menyuruh anak-anak mereka datang. Dia harus membujuk atau merayu sedemikian rupa pada anak yang akan diajari agar orang tuanya tidak tersinggung.

Dominasi patriarki membuat perempuan pelantun hanya mampu mengajarkan hahiwang pada orang-orang terdekat saja (keluarga atau tetangga). Konstruksi sosial demikian menghendaki perempuan agar "taat aturan" atau tidak boleh berlaku sembarangan terhadap orang-orang yang lebih tinggi statusnya. Disadari atau tidak, Agen-agen sosial (mulai dari keluarga, sekolah, hingga masyarakat), memelihara praktik tersebut yang justru mempertahankan ketimpangan gender.

Hasilnya, saat ini tradisi hahiwang hampir ditinggalkan oleh masyarakat Pesisir Barat. Pelantunnya hanya didominasi oleh orang tua-tua penikmat hahiwang serta para seniman saja. Sementara generasi muda hampir melupakannya. Hanya beberapa gelintir saja yang mau menggeluti hahiwang. Sisanya cenderung memilih seni tradisi lain yang lebih mudah dipelajari.

Untuk lebih jelasnya mengenai tahap perkembangan beserta fungsi hahiwang dapat dilihat pada tabel 1 di bawah ini.

Tabel 2. Tahap Perkembangan Hahiwang

\begin{tabular}{lll}
\hline No & \multicolumn{1}{c}{ Tahap } & \multicolumn{1}{c}{ Fungsi } \\
\hline & & $\begin{array}{l}\text { Sarana penghibur diri } \\
\text { dari kungkungan }\end{array}$ \\
& & Dominasi laki-laki \\
& & yang memarginalkan \\
& & dan mensubrodinasi \\
& Ungkapan & keran perempuan \\
1. & aan & sehingga hanya \\
& Perempuan & berkutat di sektor \\
& & domestik. Konstruksi \\
& & sosial tentang gender \\
& memposisikan \\
& &
\end{tabular}

perempuan lebih rendah serta dibuat bergantung secara sosial dan ekonomi pada laki-laki.

Hahiwang digunakan sebagai sarana penghibur diri atas ketidakberdayaan mengkaunter dominasi laki-laki. Hahiwang difungsikan sebagai kesenian atau media hiburan. Laki-laki mengeksploitasi perempuan pelantun membuat teks hahiwang sesuai dengan maksud dan tujuan tertentu, seperti pelengkap 2. Sebagai acara adat, media 2. Kesenian dakwah, dan penyampai nasihat. Laki-laki dapat melantunkan hahiwang dengan menghilangkan unsur ratapan menjadi nasihat atau petuah adat. Struktur hahiwang menjadi berpola seperti sastra tradisional pada umumnya.

Budaya patriarki membatasi pewarisan hahiwang.

Stratifikasi masyarakat yang dibentuk oleh budaya 3. Perkembangan ini membatasi ruang gerak perempuan dalam menularkan ilmu pada generasi muda. Ada aturan main tertentu yang mengatur hubungan antarstatus dalam masyarakat.

Sumber: Hasil Wawancara dengan Informan, 2016 dan 2017 
Tabel di atas menunjukkan bahwa ada perubahan fungsi hahiwang mulai dari tahap awal muncul hingga perkembangannya saat ini yang tidak terlepas dari dominasi patriarki. Pada tahap awal, hahiwang digunakan sebagai sarana pengibur diri dari kungkungan adat yang mendiskriminasi dan mensubrodinasi perempuan. Pada tahap berikutnya, hahiwang dieksploitasi oleh laki-laki menjadi sarana hiburan. Dan, tahap terakhir merupakan tahap berkurangnya eksistensi hahiwang pada masyarakat Lampung Pesisir karena aturan adat yang membatasi ruang gerak perempuan.

\section{PENUTUP}

Hahiwang sebagai khasanah tradisi masyarakat Lampung, khususnya Kabupaten Pesisir Barat, tidak lepas dari latar belakang budayanya. Perbedaan biologis antara laki-laki dan perempuan yang membedakan peran di antara keduanya menjadi dasar munculnya kesenian ini. Laki-laki dikonstruksi dan disosialisasikan dalam hubunganhubungan sosial yang lebih dominan sehingga mengungkung posisi perempuan hanya dalam sektor domestik. Konsekuensinya, perempuan menjadi tersubordinasi dan selalu bergantung pada laki-laki. Hahiwang hadir hanya sebatas penyalur kepedihan hati sekaligus "protes sosial" perempuan Saibatin Krui. Hahiwang besifat sangat personal (untuk diri sendiri) dan tidak bertujuan untuk menggulingkan dominasi laki-laki.

Dalam perkembangan selanjutnya, hahiwang malah dieksploitasi kaum patriakh menjadi sarana siar agama, pelengkap begawi adat, hingga penarik simpatisan dalam Pemilukada. Hegemoni patriarki membuat hahiwang tidak lagi bersifat personal, melainkan telah ditarik ke ranah publik dengan aturan main atau pakem seperti seni tradisi pada umumnya. Pelantun hahiwang dapat dilakukan oleh laki-laki dengan mengeliminasi unsur "ratapan" yang dikonstruksi hanya sebagai milik perempuan.

\section{DAFTAR SUMBER}

\section{Jurnal, Makalah, Laporan Penelitian,} Skripsi, dan Tesis

Danandjaja, James. 1998.

"Folklor dan Pembangunan Kalimantan Tengah: Merekonstruksi Nilai Budaya Orang Dayak Ngaju dan Ot Danum Melalui Cerita Rakyat Mereka". Dalam Metodologi Kajian Tradisi Lisan. Editor Pudentia MPSS. Jakarta: Yayasan Obor Indonesia dan Yayasan Asosiasi Tradisi Lisan.

Harsono, Dibyo. 2013.

"Upacara Lingkaran Hidup Orang Lampung", dalam Bunga Rampai Ekspresi Budaya sebagai Strategi Adaptasi. Hal. 245-268. Bandung: CV. Izda Prima.

Hermaliza, Essi. 2011.

"Sistem Kekerabatan Suku Bangsa Kluet di Aceh Selatan", dalam Jurnal Widyariset, Vol. 14 No.1, 2011. Hlm. 124.

Irwanto, Dedi. 2012.

"Kendala dan Alternatif Penggunaan Tradisi Lisan dalam Penulisan Sejarah Lokal di Sumatera Selatan", dalam Jurnal Forum Sosial, Volume V No. 2, September 2012. hlm. 123-126.

Kurnia. 2010.

Fungsi Hahiwang pada Ulun Saibatin

Krui Kecamatan Pesisir Tengah Lampung Barat. Skripsi, Fakultas Ilmu Sosial dan Ilmu Politik. Universitas Lampung, Bandar Lampung.

Masduki, Aam.

2006. Upacara Pineng Ngerabung Sanggagh pada Masyarakat Lampung. Bandung: Balai Kajian Sejarah dan Nilai Tradisional.

Rudito, Bambang. 2013.

"Etnografi", Makalah pada Bimbingan Teknis Penelitian 2013, Balai Pelestarian Nilai Budaya Bandung.

Sedyawati, Edi. 1996.

"Kedudukan Tradisi Lisan dalam Ilmu-ilmu Sosial dan Ilmu-ilmu Budaya", dalam Warta Atl. Jurnal Pengetahuan dan Komunikasi Peneliti 
dan Pemerhati Tradisi Lisan. Edisi II Maret. Jakarta: ATL.

Wiyatmi. 2015.

"Menggugat Kuasa Patriarki melalui Sastra Feminis", makalah pada Seminar Nasional Bahasa, Sastra, dan Kekuasaan di Universitas Negeri Yogyakarta, 26 November 2015.

\section{Buku}

Fakih, Mansour. 1997.

Analisis Gender dan Transformasi Sosial, cet.2. Yogyakarta: Pustaka Pelajar.

Hadikusuma, Hilman. 1996.

Adat Istiadat Daerah Lampung. Bandarlampung: Bagian Proyek Pengkajian dan Pembinaan Nilai-nilai Budaya Daerah Lampung.

Koentjaraningrat. 1985.

Pengantar Ilmu Antropologi. Jakarta Aksara Baru. Hlm 129-130.

Lampung Barat Dalam Angka 2013. 2013.

Liwa: Badan Pusat Statistik Kabupaten Lampung Barat.

Pudentia MPSS (ed). 1998. Metodologi Kajian Tradisi Lisan. Jakarta: Yayasan Obor Indonesia dan Yayasan Asosiasi Tradisi Lisan.

Sanusi, A. Effendi. 2001.

Sastra Lisan Lampung. Bandar Lampung: Universitas Lampung.

\section{Surat Kabar dan Majalah}

Fattah, Fauzi.

"Menyingkap Makna Filosofis Hahiwang", Lampung Post, Sabtu, 20 Juli 2013, hlm. 12.

\section{Internet}

"Bahasa Lampung", diakses dari https://khufronimi9.wordpress.com/ba hasa-lampung/, tanggal 15 Januari 2017, pukul 00.10 WIB.

Herwanto, AM. 2012. "Diskriminasi Gender dan Hegemoni Patriarkhi", diakses dari http://herwanto-a-dfisip.web.unair.ac.id/artikel_detail68475-UmumDiskriminasi\%20 Gender\%20dan\%20Hegemoni\%20Pat riarkhi.html, tanggal 15 Desember 2016, pukul 10.34 WIB.

Imron, Ali. 2014. "Selayang Pandang Kabupaten Pesisir Barat Propinsi Lampung", diakses dari http://kar yaaliimron.blogspot.co.id/2014/01/sel ayang-pandang-kabupaten-pesi sirbarat.html, tanggal 20 Juli 2017, pukul 13.20 WIB

"Kabupaten Pesisir Barat", diakses dari http://uun-halimah.blogspot.co.id/ 2017/02/kabupaten-pesisir-barat. html, tanggal 20 Februari 2017, pukul 20.55 WIB

\section{Informan}

Yalissani, 49 tahun, SMP, Ibu Rumah Tangga, Sandaran Agung Penggawa 5 Krui, Lampung Pesisir.

Mardiah, 61 tahun, SPG, Ibu Rumah Tangga, Sandaran Agung Penggawa 5 Krui, Lampung Pesisir.

Lakma Dewi, 54 tahun, SMP, Seniwati, Sandaran Agung Penggawa 5 Krui, Lampung Pesisir.

Zulhaidar, 48 tahun, SMA, Seniman, Way Suluh, Pesisir Barat.

Cik Den Hamdan, 45 tahun, SMA, Pegawai Negeri Sipil, Liwa, Lampung Barat 